\title{
Experimental investigations on machining characteristics of Al 6061 hybrid metal matrix composites processed by electrical discharge machining
}

\author{
C. Velmurugan ${ }^{1}$, R.Subramanian ${ }^{2}$, S.Thirugnanam ${ }^{3}$, B.Ananadavel $^{4}$ \\ ${ }^{1 *}$ Department of Mechanical Engineering, Kumaraguru College of Technology, Coimbatore, INDIA \\ ${ }^{2,4}$ Department of Metallurgical Engineering, PSG College of Technology, Coimbatore, INDIA \\ ${ }^{3}$ Department of Mechanical Engineering, Valliammai Engineering College, kattangulathur, INDIA \\ *Corresponding Author: e-mail: c_velmurugan16@yahoo.co.in, Tel +91-422-2669401, Fax. +91-422-2669406
}

\begin{abstract}
Metal matrix composites, in particular, Aluminium Matrix Composites are gaining increasing attention for applications in aerospace, defence and automobile industries. The use of nonconventional machining techniques in shaping aluminum metal matrix composites has generated considerable interest as the manufacturing of complicated contours such as dies. Electrical discharge machining (EDM) appears to be a promising technique for machining metal matrix composites. The objective of this work is to investigate the effect of parameters like Current(I), Pulse on time(T), Voltage(V) and Flushing pressure(P) on metal removal rate (MRR), tool wear rate(TWR) as well as surface roughness(SR) on the machining of hybrid Al6061 metal matrix composites reinforced with $10 \% \mathrm{SiC}$ and $4 \%$ graphite particles. Composite was fabricated using stir casting process. A central composite rotatable design was selected for conducting experiments. Mathematical models were developed using the MINITAB R14 software. The method of least squares technique was used to calculate the regression coefficients and Analysis of Variance (ANOVA) technique was used to check the significance of the models developed. Scanning Electron Microscope (SEM) analysis was done to study the surface characteristics of the machined specimens and correlated with the models developed.
\end{abstract}

Keywords: Electrical discharge machining, Metal matrix composites, Response surface method, Hybrid composites, Aluminium composites, stir casting process.

\section{Introduction}

Composite refers to a material system which is composed of a discrete constituent (the reinforcement) distributed in a continuous phase (the matrix) and which derives its distinguishing characteristics from the properties of its constituents, from the geometry and architecture of the constituents as well as from the properties of the boundaries(interfaces) between different constituents (Surappa, 2003). Metal Matrix Composites (MMC's) have many advantages over monolithic metals including higher specific modules, higher specific strength, better properties at elevated temperatures, lower coefficient of thermal expansion, in addition to better wear resistance. Aluminium and its alloys have been getting most attention as matrix material for MMC's and the most common reinforcement is $\mathrm{SiC}$ (Rosso, 2006). Aluminum matrix composites refer to the class of light weight high performance aluminum centric material systems. Properties of aluminum matrix composites can be tailored to the demands of different industrial applications by suitable combinations of matrix, reinforcement and processing route. Aluminium composites containing solid lubricants such as graphite and $\mathrm{MOS}_{2}$ showed better friction and wear behaviour (Mihaly Kozma, 2003). Aluminum matrix composites are produced by powder metallurgy, stir casting, metal infiltration, spraying and insitu processing techniques. These composites have been successfully used as components in automotive and aerospace applications (Torralba et al., 2003).

EDM is used in modern manufacturing industry to produce high-precision machining of all types of conductive materials, alloy's and even ceramic materials with any hardness and shape, which would have been difficult to manufacture by conventional machining. Electrical Discharge Machining (EDM) is a non-traditional machining process that uses thermo-electric energy for 
material removal. The material is removed by the erosive action of spatially discrete high-frequency electrical discharges (sparks) of high power density between two electrodes, one being the tool and the other being the work piece itself with a dielectric fluid in the gap between them. The application of dielectric fluid makes it possible to flush away eroded particles from the gap and cool it (Banerjee et al., 2008). Electrical discharge machining provides an economical and effective method for machining high strength, heat resistant materials for complex shapes (George et al., 2004; Leesh and Li Xp, 2001, Mahdavinejad and Mahdavinejad, 2005). Among the many unconventional processing techniques, EDM has proved to be effective in machining composite materials (Lauws et al., 1999; Muller and Monaghan 2000). Various researchers have conducted experiments on EDM with different composites.

Patel et al. (2010) reported that better metal removal rate and lower surface roughness of $\mathrm{Al}_{2} \mathrm{O}_{3}-\mathrm{SiC}_{\mathrm{w}}-\mathrm{TiC}$ ceramic composite during EDM was obtained for discharge current, pulse-on time, duty cycle and gap voltage $7 \mathrm{~A}, 50 \mu \mathrm{s}, 0.80$ and $50 \mathrm{~V}$, respectively. Nilesh Ganpatrao Patil \& Brahmankar, 2010, investigated the electric discharge machining characteristics of silicon carbide particulate reinforced aluminium matrix composites. They found that increased percentage of ceramic particulates in the MMC causes decreased MRR. The decrease in MRR is almost 12\% with an increase of 10\% in ceramic reinforcements. Khanra, 2005 reported that metal removal rate and tool wear rate increased with increase in applied current and pulse on time. Kung et al.. (2009) reported that electrode wear rate apparently increase with the increase of the discharge current and pulse on time. Ahamed et al. (2009) reported on the application of EDM to machine cast aluminum-silicon carbide-glass hybrid metal matrix composites and how the metal removal rate and surface finish vary in response to the various EDM parameters. They found that the metal removal rate increases with increase in flushing pressure. Based on the above considerations, a limited work has been carried out on electric discharge machining of hybrid composites. The major contribution in this research work is to fabricate a hybrid composite containing silicon carbide and graphite particles using stir casting process and its machining characteristics were studied. The objective of the present paper is to develop mathematical models for correlating the direct and interactive influences of the various machining parameters such as current, voltage, pulse on time, flushing pressure on the predominant machining criteria, i.e., the metal removal rate, tool wear rate, and surface roughness. Influence of EDM process parameters on machining performance criteria were studied with the development of mathematical models based on Response Surface Methodology (RSM).

\section{Material preparation}

The matrix material used in this study is Al6061 alloy. The reinforcement materials added were SiC and graphite particles. The addition of $\mathrm{SiC}$ particle improves the wear resistance and brittleness. The graphite particles act as solid lubricant which improve the surface finish and reduce the heat generation during machining. The composites were prepared using stir casting process. Al6061 alloy is kept in graphite crucible inside the electric induction furnace. The alloy was melted to the desired super heating temperature of $1063^{\circ} \mathrm{K}$. The preheated reinforcement particles with an amount of $10 \mathrm{wt} \%$ of $\mathrm{SiC}$ and $4 \mathrm{wt} \%$ of graphite particles and an average size of 75 microns was introduced into the vortex of the molten alloy after effective degassing. Mechanical stirring of the molten alloy for a duration of $15 \mathrm{mins}$ was achieved by using a graphite stirrer (Velmurugan et al., 2011). The speed of the stirrer was maintained at $600 \mathrm{rpm}$. The melt was poured at $873^{\circ} \mathrm{K}$ into a cast iron mould. Then the mould was left in air to cool down to room temperature and then the cast composites were obtained.

\section{Experimental work}

A series of experiments were conducted using ARD-make die-sinking EDM machine as shown in Figure 1. A tool made of copper with diameter $10 \mathrm{~mm}$ was used as an electrode.

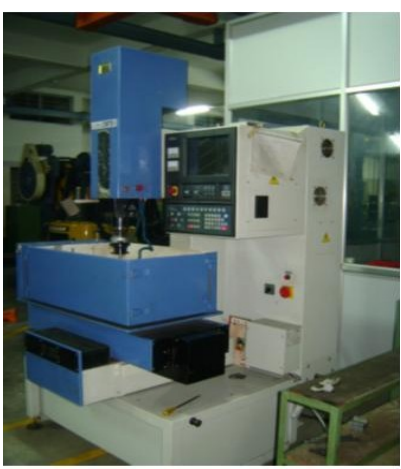

Figure 1: ARD-make die sinking machine

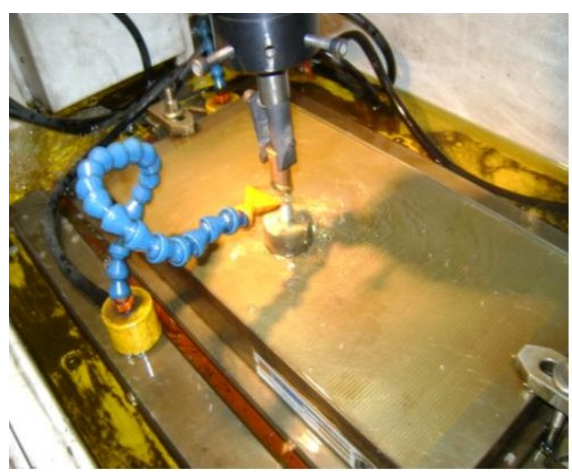

Figure 2: Jet flushing system

The other electrode was Al6061 composites reinforced with 10wt. \% SiC and 4wt. \%. of graphite particles. The size of the work piece is $10 \mathrm{~mm}$ diameter and $25 \mathrm{~mm}$ length. The density and Rockwell hardness of the composite are $2.7313 \mathrm{~g} / \mathrm{cm}^{3}$ and $68 \mathrm{HRB}$ 
respectively. Commercial grade EDM oil (density $=0.85$, flash point $=130^{\circ} \mathrm{C}$ ) was used as dielectric fluid and the side injection of dielectric fluid was adopted. A jet flushing system shown in Figure 2, was employed to assure adequate flushing of the debris from the gap zone. The process parameters were being set in the EDM machine and the experiments were conducted as per the design matrix as shown in Table 2. After each experiment the weights of specimen and electrode are measured with an electronic weighing machine.

\section{Experimental procedure}

The experimental procedure is shown in Figure 3 and important steps are briefly explained in the following sections.

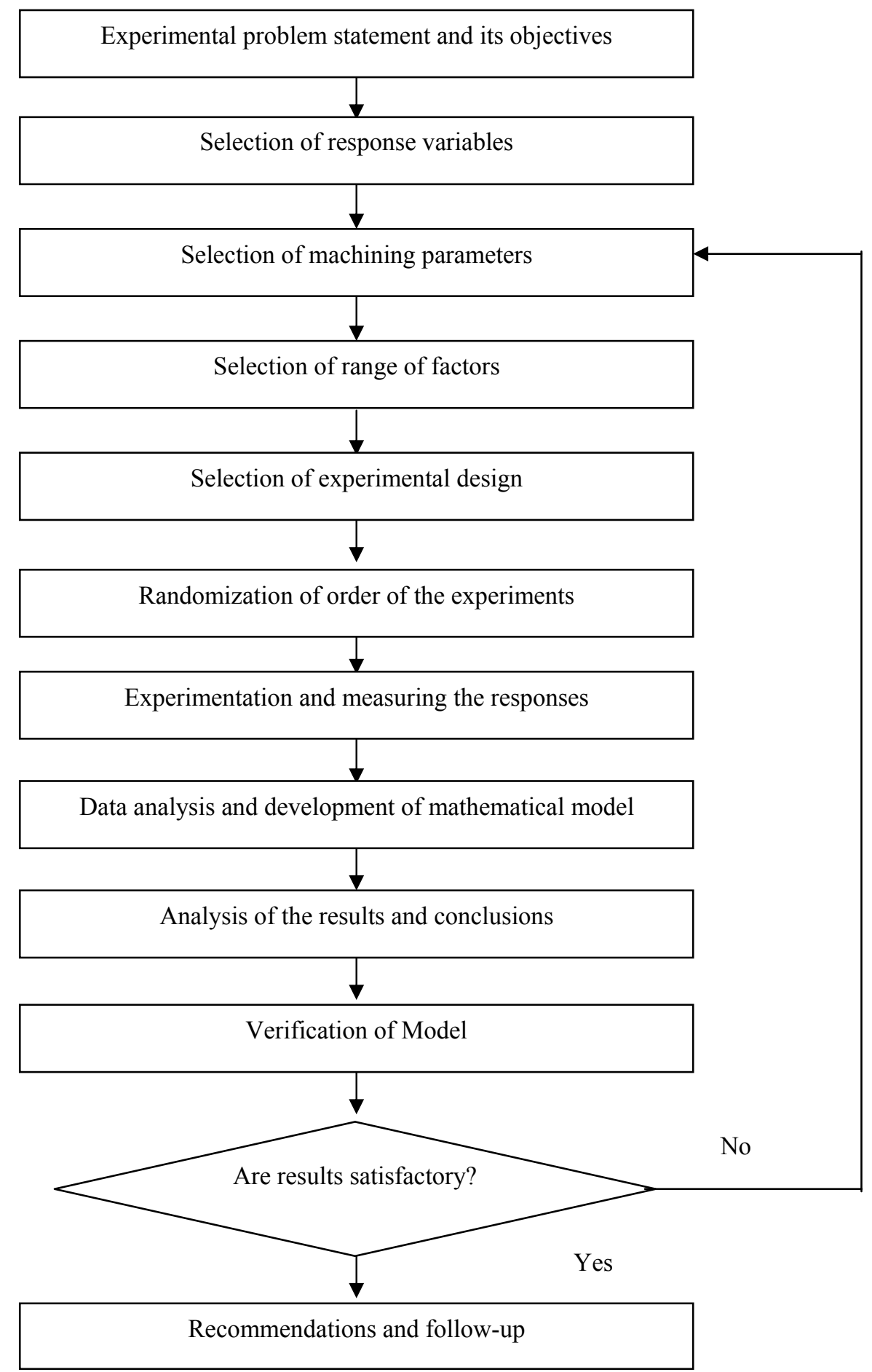

Figure 3: Experimental procedure 


\subsection{Machining parameters and response variables}

Four controllable machining parameters were identified namely, current, pulse on time, voltage and flushing pressure. On the basis of preliminary experiments conducted using one variable at a time approach, the range of the current, pulse on time, voltage and flushing pressure were selected as 3 to $15 \mathrm{~A}, 200$ to $600 \mu \mathrm{s}, 30$ to $70 \mathrm{~V}$ and 1 to 5 psi respectively. At current values less than $3 \mathrm{~A}$, it was observed that metal removal rate (MRR) was not significant and for current values more than 15A, the surface finish of the work piece was poor necessitating the selection of the intermediate values as stated above. The range selected for the pulse on time was commonly used for the EDM of ceramic composites. The range of voltage selected was available in the machine. When the flushing pressure less than $1 \mathrm{psi}$, it was observed that more tool wear occurred and for flushing pressure greater than 5 psi, work piece surface finish was poor. Control parameters and their levels are given in Table 1. The response variables selected for this work are metal removal rate (MRR), tool wear rate (TWR) and surface roughness (SR). Machining time for each experiment was taken as 10 minutes.

Table 1 Machining parameters and their levels

\begin{tabular}{|l|c|c|c|c|c|c|c|}
\hline \multirow{2}{*}{$\begin{array}{c}\text { Machining } \\
\text { parameters }\end{array}$} & \multirow{2}{*}{ symbols } & \multirow{2}{*}{ unit } & \multicolumn{6}{c|}{ Level } \\
\cline { 5 - 8 } & & & -2 & -1 & 0 & +1 & +2 \\
\hline Current & $\mathrm{I}$ & $\mathrm{A}$ & 3 & 6 & 9 & 12 & 15 \\
\hline Pulse on time & $\mathrm{T}$ & $\mu \mathrm{s}$ & 200 & 300 & 400 & 500 & 600 \\
\hline Voltage & $\mathrm{V}$ & $\mathrm{V}$ & 30 & 40 & 50 & 60 & 70 \\
\hline Flushing Pressure & $\mathrm{P}$ & $\mathrm{psi}$ & 1 & 2 & 3 & 4 & 5 \\
\hline
\end{tabular}

\subsection{Response variables evaluation}

Metal removal rate (MRR) is expressed as the ratio of the difference of weight of the work piece before and after machining to the machining time, i.e.:

$$
\operatorname{MRR}=\left[\frac{W_{j b}-W_{j a}}{t}\right] \quad(\mathrm{g} / \mathrm{min})
$$

where $W_{j b}$ and $W_{j a}$ are the weights of the work piece before and after machining, and $t$ is the machining time.

Tool wear rate is expressed as the ratio of the difference of weight of the tool before and after machining to the machining time, i.e.:

$$
\mathrm{TWR}=\left[\frac{W_{t b}-W_{t a}}{t}\right] \quad(\mathrm{g} / \mathrm{min})
$$

where $W_{t b}$ and $W_{t a}$ are the weights of the tool before and after machining and $t$ is the machining time.

MRR and TWR are directly calculated from the experimental data. The weight of the specimen is taken before and after the machining process using a digital weighing machine with an accuracy of $0.001 \mathrm{~g}$. Before weighing, the specimen is cleaned and dried to relieve it from debris and dirt. The difference of weight before and after machining gives the weight loss of the work piece during machining process. This weight is divided with machining time to get the metal removal rate and tool wear rate in $\mathrm{g} / \mathrm{min}$.

Surface roughness of the machined work piece is evaluated using a Mitutoyo talysurf tester shown in Figure 4 with a diamond stylus tip and a sampling length of $8 \mathrm{~mm}$. The centre line average value of surface roughness $\left(\mathrm{R}_{\mathrm{a}}\right.$ in micron) for each experiment was obtained directly from the tally profile software integrated with the machine.

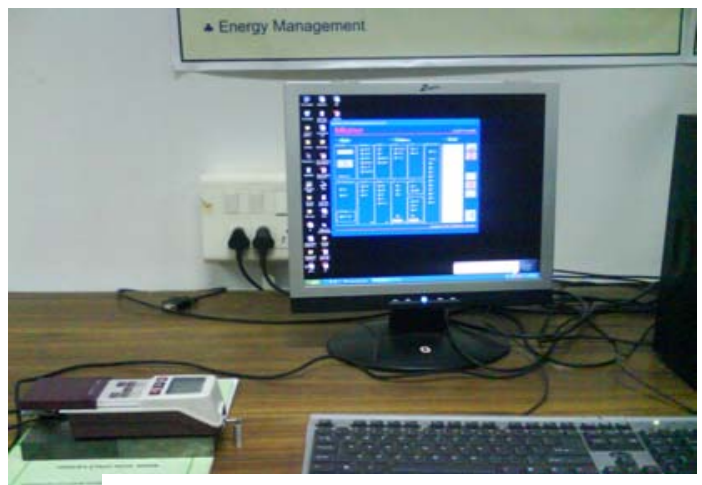

Figure 4: Surface roughness tester 


\subsection{Design of Experiments}

In the present investigation, experiments were designed on the basis of the Design of Experiments (DOE) technique proposed by Box and Hunter (Cochran and Cox, 1987). A $2^{\mathrm{k}}$ factorial, where $\mathrm{k}$ is the number of variables, with central composite second-order rotatable design was used to improve the reliability of results and to reduce the size of experimentation without loss of accuracy.

In this work, central composites rotatable design was selected for experimentation. The process parameter selected for the present work were current, voltage, pulse on time and flushing pressure and the effect of these parameters on the metal removal rate, tool wear rates and surface roughness were studied. The working ranges of all selected factors were set by conducting trial runs with one of the factors was varied while keeping rest of them at constant values (Kuppan et al., 2006; Murugan and Parmar, 1995). The levels of each factor were chosen as $-2,-1,0,1$, and 2 in closed form to have a rotatable design.

The coded values for intermediate values of a variable were calculated using the following Eq. (3)

$$
X_{i}=\frac{2\left[2 X-\left(X_{\text {max }}+X_{\text {min }}\right)\right]}{X_{\text {max }}-X_{\text {min }}}
$$

where $X_{i}$ is the required coded value of a variable $X, X$ any value of the variable from $X_{\min }$ to $X_{\max }, X_{\min }$ the lower limit of the variable, and $\mathrm{X}_{\max }$ the upper limit of the variable.

For the four variables chosen the central composite rotatable design required 31 experiments with 16 factorial points, eight axial points to form central composite design and seven center points for replication to estimate the experimental error. The experiment has been carried out according to the run order in the experiment design matrix as given in Table2. At the end of each run, settings for all four parameters were changed and reset for the next run. This was essential to introduce variability caused by errors in experimental settings (Harris and Smith, 1983).

Table2 Design Matrix

\begin{tabular}{|c|c|c|c|c|c|c|c|c|c|c|c|}
\hline \multirow{2}{*}{$\begin{array}{l}\text { Run } \\
\text { order }\end{array}$} & \multirow{2}{*}{$\begin{array}{l}\text { Std. } \\
\text { Ord } \\
\text { er }\end{array}$} & \multirow{2}{*}{$\begin{array}{l}\text { Current } \\
\text { (I) } \mathrm{A}\end{array}$} & \multirow{2}{*}{$\begin{array}{l}\text { Pulse } \\
\text { on } \\
\text { time } \\
(\mathrm{T}) \mu \mathrm{s}\end{array}$} & \multirow{2}{*}{$\begin{array}{l}\text { Voltage } \\
\text { (V) V }\end{array}$} & \multirow{2}{*}{$\begin{array}{l}\text { Flushing } \\
\text { pressure } \\
(\mathrm{P}) \mathrm{psi}\end{array}$} & \multicolumn{3}{|c|}{ Experimental value } & \multicolumn{3}{|c|}{ Predicted value } \\
\hline & & & & & & $\begin{array}{l}\text { MRR } \\
(\mathrm{g} / \mathrm{min})\end{array}$ & $\begin{array}{l}\text { TWR } \\
\text { (g/min) }\end{array}$ & $\begin{array}{l}\text { SR } \\
\left(\times 10^{-1}\right. \\
\mu \mathrm{m})\end{array}$ & $\begin{array}{l}\text { MRR } \\
(\mathrm{g} / \mathrm{min})\end{array}$ & $\begin{array}{l}\text { TWR } \\
\text { (g/min) }\end{array}$ & $\begin{array}{l}\text { SR } \\
\left(\times 10^{-1}\right. \\
\mu \mathrm{m})\end{array}$ \\
\hline 1 & 6 & 1 & -1 & 1 & -1 & 0.481 & 0.044 & 65 & 0.480 & 0.045 & 68.253 \\
\hline 2 & 12 & 1 & 1 & -1 & 1 & 0.53 & 0.026 & 91 & 0.542 & 0.026 & 93.586 \\
\hline 3 & 27 & 0 & 0 & 0 & 0 & 0.464 & 0.034 & 81 & 0.486 & 0.033 & 80.143 \\
\hline 4 & 18 & 2 & 0 & 0 & 0 & 0.583 & 0.036 & 91 & 0.552 & 0.036 & 86.310 \\
\hline 5 & 14 & 1 & -1 & 1 & 1 & 0.515 & 0.041 & 105 & 0.507 & 0.041 & 104.086 \\
\hline 6 & 31 & 0 & 0 & 0 & 0 & 0.491 & 0.035 & 85 & 0.486 & 0.033 & 80.143 \\
\hline 7 & 10 & 1 & -1 & -1 & 1 & 0.524 & 0.031 & 84 & 0.527 & 0.031 & 83.753 \\
\hline 8 & 7 & -1 & 1 & 1 & -1 & 0.449 & 0.037 & 68 & 0.429 & 0.037 & 71.920 \\
\hline 9 & 22 & 0 & 0 & 2 & 0 & 0.419 & 0.048 & 94 & 0.435 & 0.046 & 91.250 \\
\hline 10 & 23 & 0 & 0 & 0 & -2 & 0.431 & 0.039 & 45 & 0.459 & 0.037 & 44.310 \\
\hline 11 & 1 & -1 & -1 & -1 & -1 & 0.45 & 0.032 & 40 & 0.434 & 0.032 & 41.753 \\
\hline 12 & 29 & 0 & 0 & 0 & 0 & 0.464 & 0.031 & 77 & 0.486 & 0.033 & 80.143 \\
\hline 13 & 24 & 0 & 0 & 0 & 2 & 0.521 & 0.03 & 111 & 0.513 & 0.029 & 115.976 \\
\hline 14 & 30 & 0 & 0 & 0 & 0 & 0.497 & 0.034 & 79 & 0.486 & 0.033 & 80.143 \\
\hline 15 & 4 & 1 & 1 & -1 & -1 & 0.51 & 0.029 & 56 & 0.515 & 0.030 & 57.753 \\
\hline 16 & 19 & 0 & -2 & 0 & 0 & 0.476 & 0.041 & 64 & 0.471 & 0.039 & 68.075 \\
\hline 17 & 25 & 0 & 0 & 0 & 0 & 0.483 & 0.033 & 80 & 0.486 & 0.033 & 80.143 \\
\hline 18 & 28 & 0 & 0 & 0 & 0 & 0.486 & 0.034 & 81 & 0.486 & 0.033 & 80.143 \\
\hline 19 & 15 & -1 & 1 & 1 & 1 & 0.454 & 0.033 & 108 & 0.456 & 0.033 & 107.753 \\
\hline 20 & 20 & 0 & 2 & 0 & 0 & 0.542 & 0.031 & 89 & 0.510 & 0.030 & 89.976 \\
\hline 21 & 21 & 0 & 0 & -2 & 0 & 0.495 & 0.027 & 48 & 0.474 & 0.026 & 50.584 \\
\hline 22 & 11 & -1 & 1 & -1 & 1 & 0.461 & 0.022 & 89 & 0.475 & 0.023 & 87.420 \\
\hline 23 & 26 & 0 & 0 & 0 & 0 & 0.495 & 0.033 & 78 & 0.486 & 0.033 & 80.143 \\
\hline 24 & 13 & -1 & -1 & 1 & 1 & 0.451 & 0.036 & 98 & 0.441 & 0.038 & 97.920 \\
\hline 25 & 16 & 1 & 1 & 1 & 1 & 0.519 & 0.036 & 110 & 0.522 & 0.036 & 113.920 \\
\hline 26 & 5 & -1 & -1 & 1 & -1 & 0.441 & 0.042 & 62 & 0.420 & 0.042 & 62.086 \\
\hline 27 & 8 & 1 & 1 & 1 & -1 & 0.492 & 0.039 & 74 & 0.495 & 0.040 & 78.086 \\
\hline 28 & 2 & 1 & -1 & -1 & -1 & 0.498 & 0.035 & 48 & 0.500 & 0.035 & 47.920 \\
\hline 29 & 9 & -1 & -1 & -1 & 1 & 0.46 & 0.028 & 78 & 0.460 & 0.028 & 77.586 \\
\hline 30 & 3 & -1 & 1 & -1 & -1 & 0.453 & 0.025 & 52 & 0.449 & 0.026 & 51.586 \\
\hline 31 & 17 & -2 & 0 & 0 & 0 & 0.41 & 0.031 & 73 & 0.420 & 0.030 & 73.976 \\
\hline
\end{tabular}




\subsection{Development of Mathematical models}

The function representing any of the response variables can be expressed using Eq. (4)

$$
\mathrm{Y}=\mathrm{f}\left(\mathrm{X}_{1}, \mathrm{X}_{2}, \mathrm{X}_{3}, \mathrm{X}_{4}\right)+€
$$

where $\mathrm{Y}$ is the response (e.g. metal removal rate), $€$ is the error, $\mathrm{X}_{1}$ the current (I) (A), $\mathrm{X}_{2}$ the pulse on time (T) ( $\mu$ s), $\mathrm{X}_{3}$ the voltage $(\mathrm{V})(\mathrm{V})$, and, $\mathrm{X}_{4}$ the flushing pressure $(\mathrm{P})(\mathrm{psi})$.

The second order response surface model (Montgomery, 2003) for the four selected factors is given by Eq.(5)

$$
Y=\beta_{o}+\sum_{i=1}^{4} \beta_{i} X_{i}+\sum_{i=1}^{4} \beta_{i i} X_{i}{ }^{2}+\sum_{\substack{i=1 \\ i<j}}^{4} \beta_{i j} X_{i} X_{j}
$$

The above second order response surface model equation could be expressed as follows:

$$
\begin{aligned}
& Y=\beta_{o}+\beta_{1} I+\beta_{2} T+\beta_{3} V+\beta_{4} P+\beta_{11} I^{2}+\beta_{22} T^{2}+\beta_{33} V^{2}+\beta_{44} P^{2}+\beta_{12} I T+\beta_{13} I V+ \\
& \beta_{14} I P+\beta_{23} T V+\beta_{24} T P+\beta_{34} V P
\end{aligned}
$$

where $\beta_{0}$ is the free term of the regression equation, the coefficients $\beta_{1}, \beta_{2}, \beta_{3}$ and $\beta_{4}$ are linear terms, the coefficients $\beta_{11}, \beta_{22}, \beta_{33}, \beta_{44}$ are the quadratic terms, and the coefficients $\beta_{12}, \beta_{13}, \beta_{14}, \beta_{23}, \beta_{24}$ and $\beta_{34}$ are the interaction terms of the regression equation.

The values of the coefficient of the polynomial Eq. (6) were calculated as shown by Kannan and Murugan (2006) by Eqs. (7)-(10)

$$
\begin{aligned}
& \beta_{o}=0.142857 \sum Y-0.035714 \sum \sum\left(X_{i i} Y\right) \\
& \beta_{i}=0.041667 \sum\left(X_{i} Y\right) \\
& \beta_{i i}=0.03125 \sum\left(X_{i i} Y\right)+0.035714 \sum \sum\left(X_{i i} Y\right)-0.035715 \sum Y \\
& \beta_{i j}=0.0625 \sum\left(X_{i j} Y\right)
\end{aligned}
$$

The $\beta$ coefficients, used in the above model can be calculated by means of using least square method. The regression coefficients were calculated using MINITAB R14 software and used to develop the mathematical models. The insignificant coefficients were eliminated without affecting the accuracy of the developed model. This was done by back elimination technique, available in MINITAB R14 software. The coefficients given in Table 3 are used to obtain the mathematical models. The Mathematical models developed for the response variables with machining parameters in coded form are given in equations 11-16. The insignificant coefficients are eliminated and the final reduced models are given in equations 11-13 and the full models are given in equations 14-16.

Metal removal rate $(\mathrm{MRR})(\mathrm{g} / \mathrm{min})=0.485874+(0.03316 * \mathrm{I})+(0.0075 * \mathrm{~T})-(0.00983 * \mathrm{~V})+(0.01333 * \mathrm{P})-(0.00790 * \mathrm{~V} * \mathrm{~V})$

Tool wear rate $(\mathrm{TWR})(\mathrm{g} / \mathrm{min})=0.033442+(0.0015 * \mathrm{I})-(0.00258 * \mathrm{~T})+(0.00508 * \mathrm{~V})-(0.002 * \mathrm{P})+(0.00070 * \mathrm{~V} * \mathrm{~V})$

Surface roughness $(\mathrm{SR})(\mu \mathrm{m})=80.1429+(3.0833 * \mathrm{I})+(4.9167 * \mathrm{~T})+(10.1667 * \mathrm{~V})+(17.9167 * \mathrm{P})-\left(2.3065^{*} \mathrm{~V} * \mathrm{~V}\right)$

Metal removal rate $(\mathrm{MRR})(\mathrm{g} / \mathrm{min})=0.485874+(0.03316 * \mathrm{I})+(0.0075 * \mathrm{~T})-(0.00983 * \mathrm{~V})+(0.01333 * \mathrm{P})+(0.002723 * \mathrm{I} * \mathrm{I})+$ $(0.005848 * \mathrm{~T} * \mathrm{~T})-(0.007152 * \mathrm{~V} * \mathrm{~V})-(0.002402 * \mathrm{P} * \mathrm{P})+(0.001125 * \mathrm{I} * \mathrm{~T})-(0.001625 * \mathrm{I} * \mathrm{~V})+(0.004625 * \mathrm{I} * \mathrm{P})+(0.000250 * \mathrm{~T} * \mathrm{~V})-$ $(0.001250 * \mathrm{~T} * \mathrm{P})+(0.000750 * \mathrm{~V} * \mathrm{P})$

Tool wear rate $(\mathrm{TWR})(\mathrm{g} / \mathrm{min})=0.033442+(0.0015 * \mathrm{I})-(0.00258 * \mathrm{~T})+(0.00508 * \mathrm{~V})-(0.002 * \mathrm{P})-(0.000295 * \mathrm{I} * \mathrm{I})+(0.000330 * \mathrm{~T} * \mathrm{~T})$ $+(0.00790 * \mathrm{~V} * \mathrm{~V})-(0.000045 * \mathrm{P} * \mathrm{P})-(0.000001 * \mathrm{I} * \mathrm{~T})-(0.000125 * \mathrm{I} * \mathrm{~V})+(0.000250 * \mathrm{I} * \mathrm{P})+(0.000375 * \mathrm{~T} * \mathrm{~V})+(0.000250 * \mathrm{~T} * \mathrm{P})-$ $\left(0.000125 * \mathrm{~V}^{*} \mathrm{P}\right)$

Surface roughness $(\mathrm{SR})(\mu \mathrm{m})=80.1429+(3.0833 * \mathrm{I})+(4.9167 * \mathrm{~T})+(10.1667 * \mathrm{~V})+(17.9167 * \mathrm{P}))+(0.4435 * \mathrm{I} * \mathrm{I})-(0.9315 * \mathrm{~T} * \mathrm{~T})$ - $(2.3065 * \mathrm{~V} * \mathrm{~V})-(0.5565 * \mathrm{P} * \mathrm{P})-(0.6250 * \mathrm{I} * \mathrm{~T})-(0.1250 * \mathrm{I} * \mathrm{~V})-(0.2500 * \mathrm{I} * \mathrm{P})-(0.5000 * \mathrm{~T} * \mathrm{~V})-(0.1250 * \mathrm{~T} * \mathrm{P})+(0.3750 * \mathrm{~V} * \mathrm{P})$ 
Table 3 Estimated values of the coefficients of the models

\begin{tabular}{|l|l|l|l|l|}
\hline Sl.No. & Coefficient & Value & \multicolumn{3}{l|}{} \\
\cline { 3 - 5 } & & MRR & TWR & SR \\
\hline 1 & $\beta_{o}$ & 0.485874 & 0.033442 & 80.1429 \\
\hline 2 & $\beta_{1}$ & 0.03316 & 0.0015 & 3.0833 \\
\hline 3 & $\beta_{2}$ & 0.0075 & -0.00258 & 4.9167 \\
\hline 4 & $\beta_{3}$ & -0.00983 & 0.00508 & 10.1667 \\
\hline 5 & $\beta_{4}$ & 0.01333 & -0.002 & 17.9167 \\
\hline 6 & $\beta_{11}$ & 0.002723 & -0.000295 & 0.4435 \\
\hline 7 & $\beta_{22}$ & 0.005848 & 0.000330 & -0.9315 \\
\hline 8 & $\beta_{33}$ & -0.00790 & 0.00070 & -2.3065 \\
\hline 9 & $\beta_{44}$ & 0.002402 & -0.000045 & -0.5565 \\
\hline 10 & $\beta_{12}$ & 0.001125 & -0.000001 & -0.6250 \\
\hline 11 & $\beta_{13}$ & -0.001625 & -0.000125 & -0.1250 \\
\hline 12 & $\beta_{14}$ & 0.004625 & 0.000250 & -0.2500 \\
\hline 13 & $\beta_{23}$ & 0.000250 & 0.000375 & -0.5000 \\
\hline 14 & $\beta_{24}$ & 0.001250 & 0.000250 & -0.1250 \\
\hline 15 & $\beta_{34}$ & 0.000750 & 0.000125 & 0.3750 \\
\hline
\end{tabular}

It was found that the reduced models are better than the full models because the reduced models have higher values of $\mathrm{R}^{2}$ than that of full models. The values of $\mathrm{R}^{2}$ for full and reduced models are given in Table 4 .

Table 4 Comparison of $\mathbf{R}^{2}$ values for full and reduced models

\begin{tabular}{|l|l|l|}
\hline \multirow{2}{*}{ Response variable } & $\mathrm{R}^{2}$ values \\
\cline { 2 - 3 } & Full model & Reduced model \\
\hline Metal removal rate (MRR) & $88.3 \%$ & $89.2 \%$ \\
\hline Tool wear rate (TWR) & $96.7 \%$ & $97.1 \%$ \\
\hline Surface roughness (SR) & $98.1 \%$ & $98.8 \%$ \\
\hline
\end{tabular}

\subsection{Verification of the adequacy of the developed models}

The adequacies of the developed models were tested using the Analysis of the Variance (ANOVA) technique (Gunaraj and Murugan, 1999). According to this technique, if the calculated F-ratio values for the developed models do not exceed the standard tabulated values of F-ratio for a desired level of confidence (95\%) then the models are said to be adequate within the confidence limit. This condition was satisfied for all the developed models, which are given in Table 5. The validity of these models was again tested by drawing scatter diagrams as shown in Figure 5a-c and error profile graph as shown in Figure 6a-c.

Table 5 Analysis of variance for testing adequacy of the models

\begin{tabular}{|c|c|c|c|c|}
\hline \multicolumn{2}{|l|}{ Parameter } & $\begin{array}{l}\text { Metal removal rate } \\
\text { (MRR) }\end{array}$ & $\begin{array}{l}\text { Tool wear rate } \\
\text { (TWR) }\end{array}$ & $\begin{array}{l}\text { Surface roughness } \\
\text { (SR) }\end{array}$ \\
\hline \multirow[t]{2}{*}{ First order terms } & SS & 0.034338 & 0.000930 & 10993.2 \\
\hline & d.f. & 4 & 4 & 4 \\
\hline \multirow{2}{*}{$\begin{array}{l}\text { Second order } \\
\text { terms }\end{array}$} & SS & 0.003691 & 0.000026 & 199.2 \\
\hline & d.f. & 10 & 10 & 10 \\
\hline \multirow[t]{2}{*}{ Lack of fit } & SS & 0.004330 & 0.000023 & 102.4 \\
\hline & d.f. & 10 & 10 & 10 \\
\hline \multirow[t]{2}{*}{ Error terms } & SS & 0.000721 & 0.000010 & 40.9 \\
\hline & d.f. & 6 & 6 & 6 \\
\hline \multicolumn{2}{|l|}{ F-ratio } & 3.60 & 1.43 & 1.50 \\
\hline \multicolumn{2}{|l|}{$\mathrm{P}$ value } & 0.161 & 0.343 & 0.320 \\
\hline \multicolumn{2}{|c|}{ Whether model is adequate } & Adequate & Adequate & Adequate \\
\hline
\end{tabular}

Standard tabulated value of F-ratio $(10,6,0.05)=4.06$; SS, Sum of Squares; d.f., degrees of freedom. 


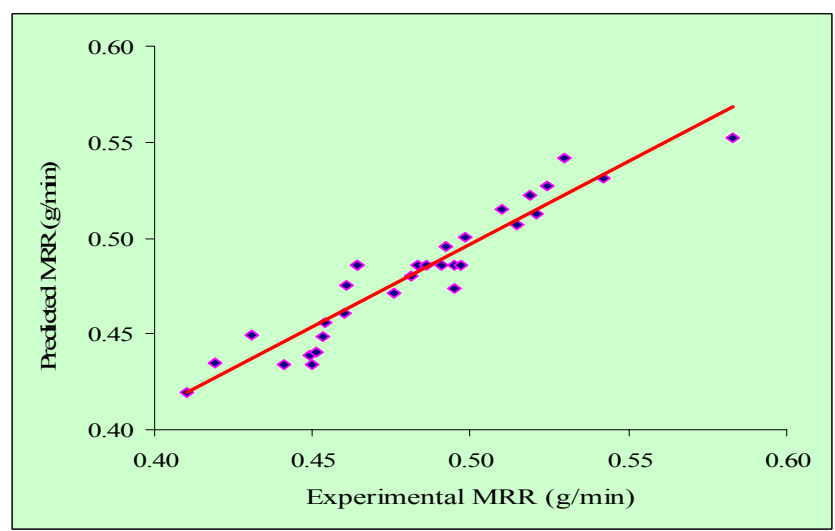

(a)

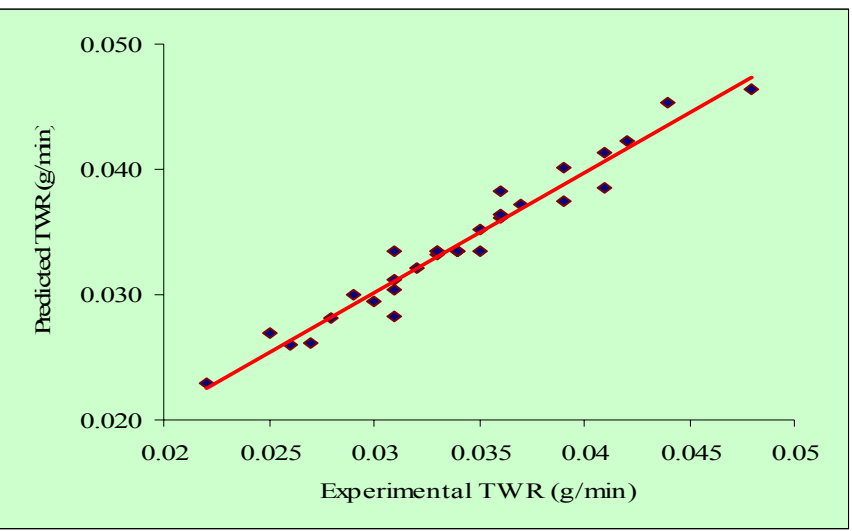

(b)

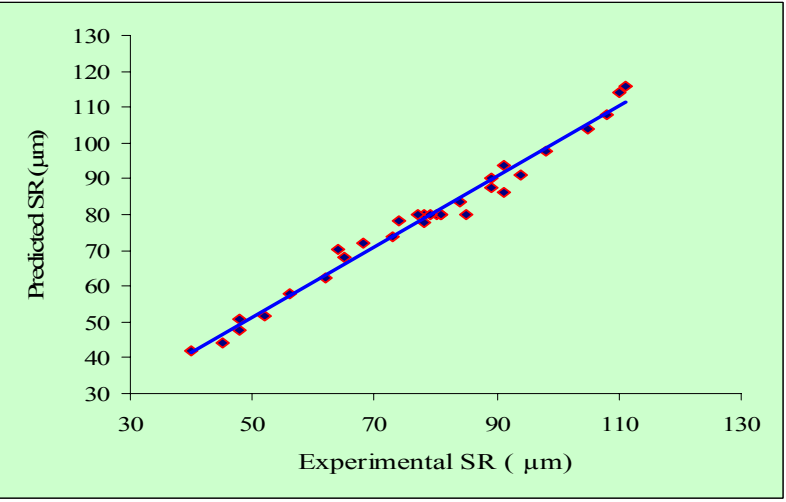

(c)

Figure 5: Scatter diagram of (a) metal removal rate model; (b) tool wear rate model; (c) surface roughness model

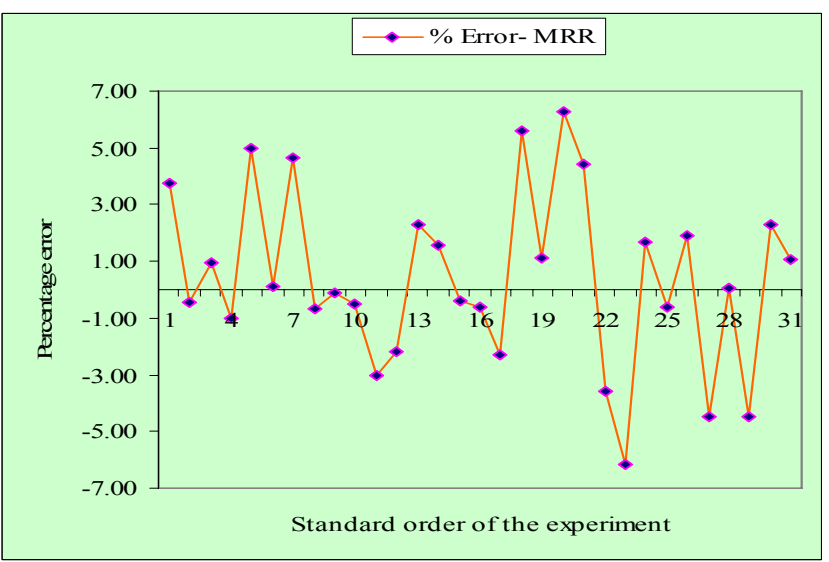

(a)

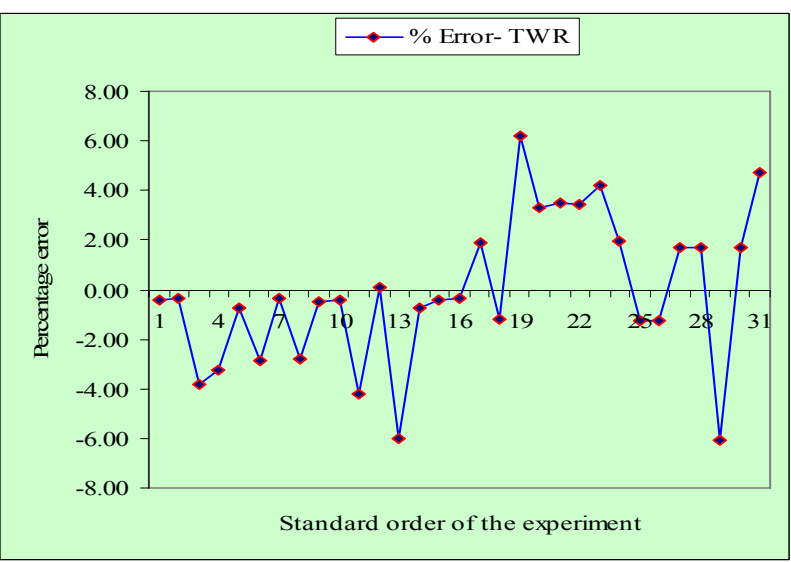

(b)

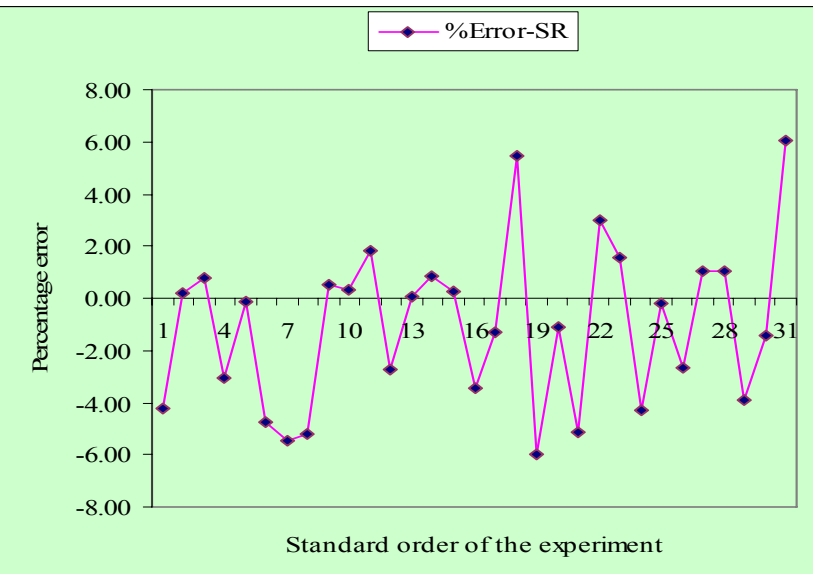

(c)

Figure 6: Error profile graph of (a) metal removal rate model; (b) tool wear rate model; (c) surface roughness model 
It was observed from the scatter diagram that the predicted values of the response variables are fairly close to the corresponding experimental values of the response variables. The error profile graph shows the percentage error between predicted values and experimental values for the response variables.

\subsection{Conformity tests}

Conformity tests were conducted using the same experimental setup to confirm the results of the experiment and demonstrate the reliability of the predicated values.

$$
\% \text { Error }=(\text { actual value }- \text { predicted value } / \text { predicted value }) \times 100
$$

Table 6 Comparison of predicted and actual values of response variables

\begin{tabular}{|l|l|l|l|l|l|l|l|l|l|l|l|l|}
\hline \multicolumn{2}{|l}{$\begin{array}{l}\text { Machining parameter in coded } \\
\text { form }\end{array}$} & \multicolumn{2}{l}{$\begin{array}{l}\text { Predicted values of response } \\
\text { variables }\end{array}$} & $\begin{array}{l}\text { Actual values of response } \\
\text { variables }\end{array}$ & \multicolumn{2}{l|}{ Error (\%) } \\
\hline I & T & V & P & $\begin{array}{l}\text { MRR } \\
(\mathrm{g} / \mathrm{min})\end{array}$ & $\begin{array}{l}\text { TWR } \\
(\mathrm{g} / \mathrm{min})\end{array}$ & $\begin{array}{l}\mathrm{SR}\left(\times 10^{-3}\right. \\
\mu \mathrm{m})\end{array}$ & $\begin{array}{l}\text { MRR } \\
(\mathrm{g} / \mathrm{min})\end{array}$ & $\begin{array}{l}\text { TWR } \\
(\mathrm{g} / \mathrm{min})\end{array}$ & $\begin{array}{l}\text { SR }\left(\times 10^{-3}\right. \\
\mu \mathrm{m})\end{array}$ & MRR & TWR & SR \\
\hline-0.12 & -0.21 & 0.08 & -0.4 & 0.474 & 0.035 & 72.372 & 0.475 & 0.034 & 73.21 & 0.21 & -2.85 & 1.16 \\
\hline-0.77 & -0.33 & 0.97 & 1.08 & 0.455 & 0.037 & 103.188 & 0.450 & 0.036 & 104.12 & -1.09 & -2.7 & 0.89 \\
\hline-0.88 & 0.06 & 0.96 & 1.11 & 0.455 & 0.035 & 105.246 & 0.452 & 0.034 & 104.66 & -0.65 & -2.85 & -0.57 \\
\hline
\end{tabular}

The conformity tests show the accuracy of the models developed, which is above 96\% (Table 6.)

\section{Results and discussion}

\subsection{Mechanism of material removal}

Conventional machining is difficult to perform on metal matrix composites due to increased tool wear and associated problems. The electrical and thermal insulating properties of the reinforcement particles generally posses problems. These problems become more severe for machining of intricate shapes. The advantage of EDM process is its capability to machine difficult to machine materials with desired shape and size with a required dimensional accuracy and productivity. The machining mechanism in electric discharge machining is melting and vaporizing of matrix material. Melting and vaporization of matrix material by the plasma channel causes detachment the reinforcement. The presence of unmelted ceramic particles with its cutting edges in the debris collected, confirmed the proposed mechanism for composites. This machining mechanism has confirmed with the earlier findings (Ponappa et al., 2009. Chiang. 2008).

The microstructure of the cast hybrid composite is shown in Figure.7. It shows that the reinforcement particles are uniformly distributed with in the matrix material. Figure 8 shows the SEM photograph of electric discharge machined surface of the composite. When the discharge current increases from 3A to 15A, electric discharges strike the surface of the work piece more intensely. Due to this, the diameter and the depth of craters of electric discharge machined surface increases hence the surface roughness consequently increases. Owing to the insulating nature of reinforcement particles, abnormal arcing and random spark discharges occur in region where micron-sized reinforcements are seen. Fall out of particles can be observed due to the impact of spark. Bands and craters observed at the machined surfaces of composites as shown in Fig. $8 \mathrm{c}$ and d confirm the irregular spark discharges during machining. In general, at low discharge energy the craters are shallow and the surface irregularities are smooth, shallow and less frequent. At high discharge energy the craters are deeper and surface irregularities are larger (Riaz Ahamed, 2009). When the flushing pressure was increased, the rate of solidification of debris scattered over the electric discharge machined surface by molten material droplets from the tool and work piece electrodes also increased. Because of this the surface roughness of the machined work piece was decreased. The obtained variation in surface roughness of the composite $(\mathrm{Ra}=4-11 \mu \mathrm{m})$ for all the selected experimental conditions is also minimal due to the flushing of debris. 


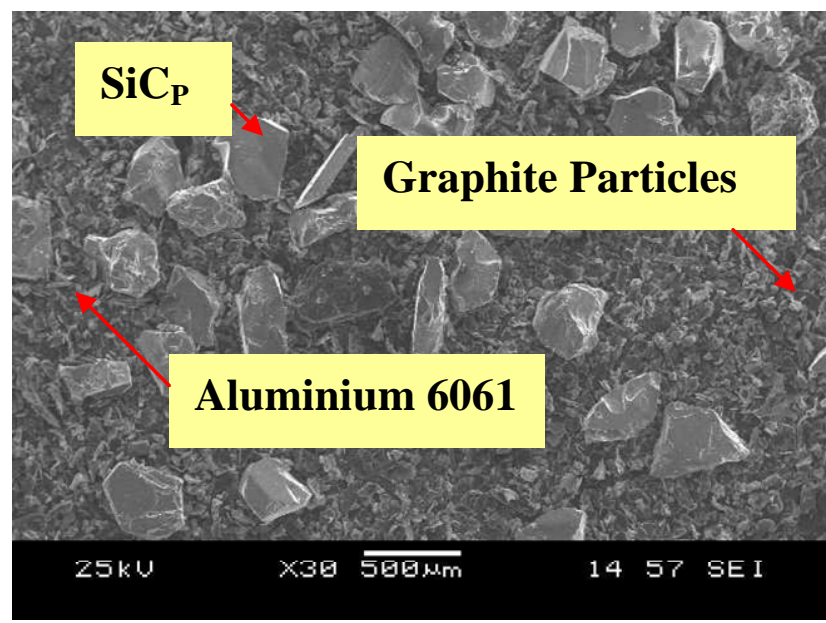

Figure 7: SEM photograph of as cast hybrid composites
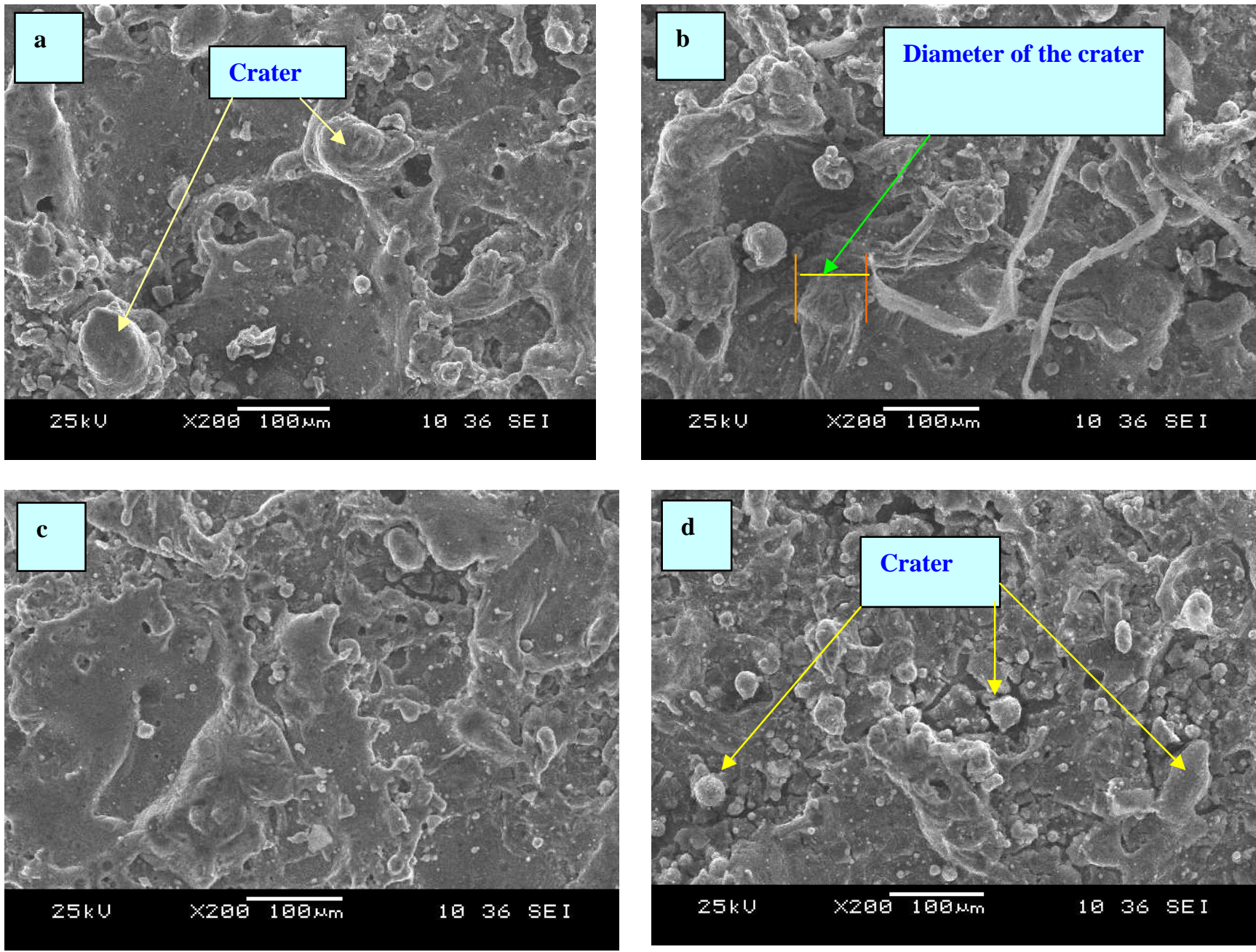

Figure 8: SEM photograph of electric discharge machined surface of Al 6061 composites reinforced with SiC and graphite particles at a voltage $50 \mathrm{~V}$ and a flushing pressure 3psi: a) $3 \mathrm{~A}, 400 \mu \mathrm{s}$, b) $15 \mathrm{~A}, 400 \mu \mathrm{s}, \mathrm{c}) 9 \mathrm{~A}, 200 \mu \mathrm{s}, \mathrm{d})$

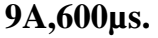




\subsection{Effect of machining parameters on response variables}

The Equations.11, 12 and 13 can be used to predict the response variables by substituting the coded values of the respective process parameters. The responses calculated from these models for each set of coded machining parameters are represented in graphical form in Figure 9-12. In addition, by substituting the values of desired response variables, the values of the machining parameters, in coded form can be obtained. The influence of process parameters such as the current, pulse on time, voltage and the surface roughness are analyzed based on mathematical models.

\subsubsection{Effect of current (I) on response variables}

Figure 9 shows the effect of current on the response variables. It is observed that the metal removal rate of the composites increases linearly with increasing the value of current. The tool wear rate slightly increasing with increasing the value of current. The increase in metal removal rate and tool wear rate is due to the fact that the spark discharge energy is increased to facilitate the action of melting and vaporization and advancing the large impulsive force in the spark gap. High current values results in higher thermal loading on both tool and work piece electrode lead to high metal removal rate and tool wear rate. The surface roughness value also slightly increases with increase in current. This is similar to the observation confirmed by other researchers (Mahdavinejad and Mahdavinejad, 2005; Narender singh et al., 2004, Simul Banerjee, 2008) who have stated that increase in current results in increasing metal removal rate, tool wear rate and surface roughness.

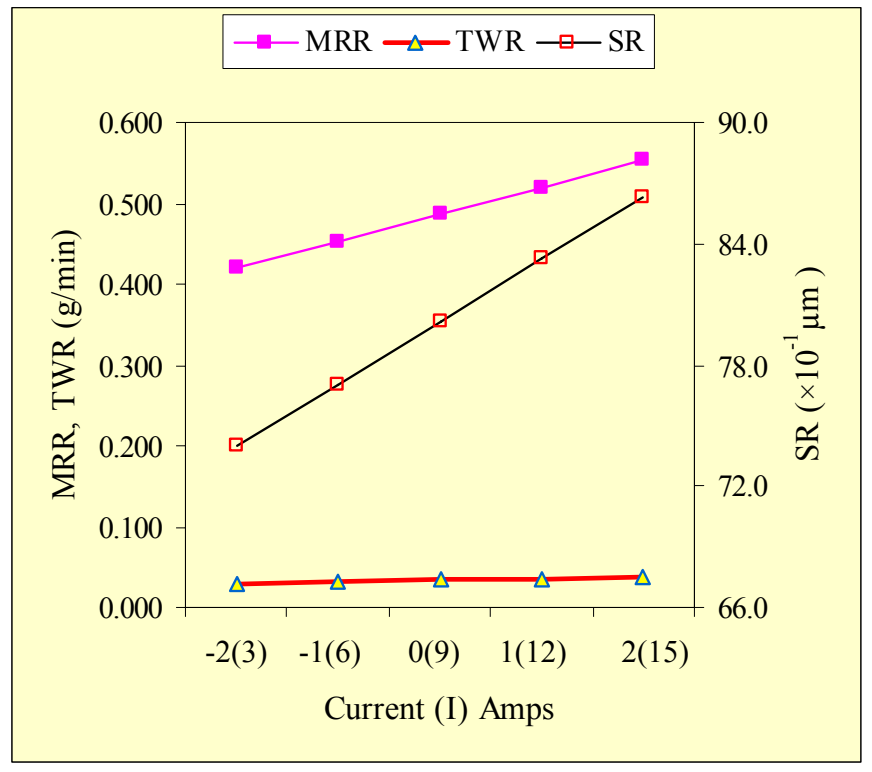

Figure 9: Effect of current on the response variables

\subsubsection{Effect of pulse on time $(T)$ on response variables}

It can be observed the effect pulse on time (T) on MRR and SR is shown in Figure 10 that the metal removal rate and surface roughness increases with increasing the value of pulse on time while the tool wear rate decreases. The increase in the pulse on time means applying the same heating temperature for longer time. This will cause an increase in the evaporation rate and the number of gas bubbles, which explode with high ejecting force when the discharge ceases, causing removal of bigger volume of the molten metal. Increase in the discharge current strengthens the pulsation energy so the material is removed more easily by higher current densities. In addition, increasing the pulse on time possibly results in the expansion of the discharge column, promoting the material removal rate and surface roughness. The coefficient $\left(\beta_{2}\right)$ associated with pulse on time (T) in the developed mathematical model for metal removal rate and surface roughness are shown in Eqs. 11 and 13 is seen to be positive and for tool wear rate shown in Eq.12 is negative. This suggests that the metal removal rate and surface roughness are directly proportional to the pulse on time whereas the tool wear rate is opposite. The decrease of tool wear rate with increase in pulse on time is very low almost constant. Reduction in tool wear rate can be attributed to the fact that rate of evaporation from tool is lower because of the presence of both silicon carbide and graphite particles in the metal. A similar observation for the effect of pulse on time on metal removal rate and surface roughness was confirmed in a previous study carried out on machining of composites using electric discharge machining (Kao et al., 2009) who has used copper as the tool material. However, the effect of pulse on time with tool wear rate is in disagreement with yet another researcher (Narender singh et al., 2004) who has stated that an increase in pulse on time results in increasing the tool wear rate due to the presence of $\mathrm{SiC}$ particles only in aluminium matrix. 


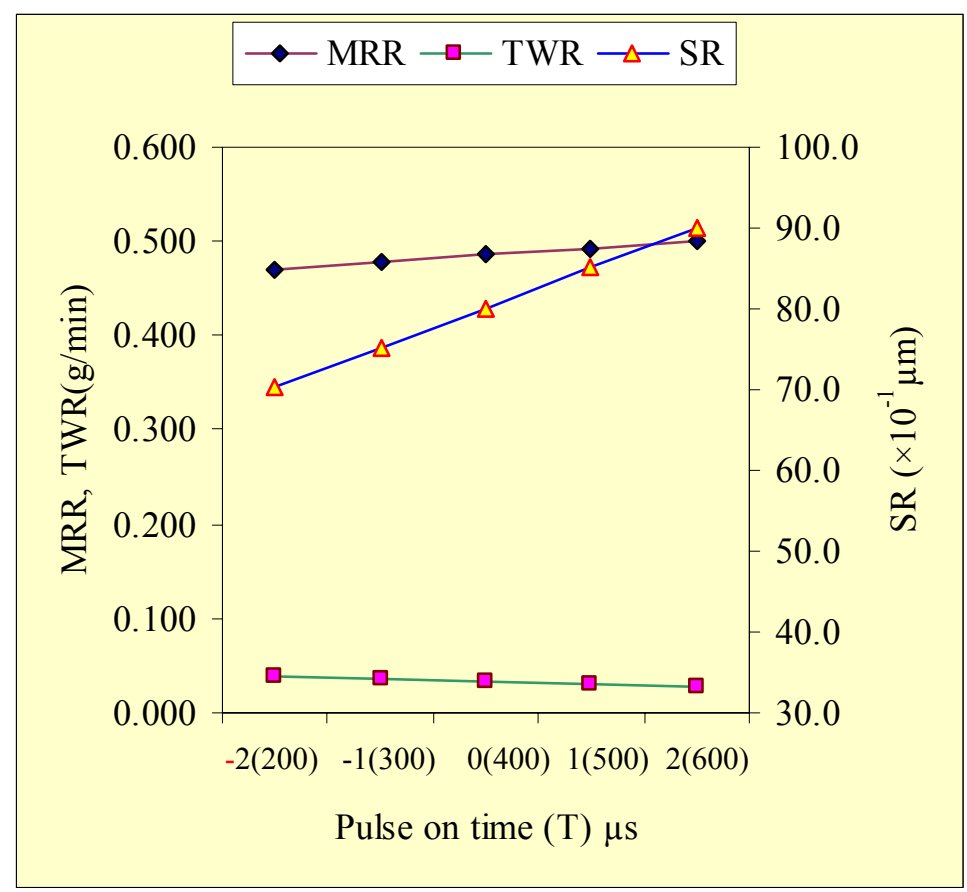

Figure 10: Effect of pulse on time on the response variables

\subsubsection{Effect of voltage $(\mathrm{V})$ on response variables}

The variation of machining parameters of the composites with voltage during EDM is shown in Figure 11. The coefficient $\left(\beta_{3}\right)$ in the developed mathematical model for tool wear rate and surface roughness associated with the voltage shown in Eqs. 12 and 13 is seen to be positive, while for metal removal rate shown in Eq.11 is negative. This suggests that the tool wear rate and surface roughness are directly proportional to the voltage whereas the metal removal rate is opposite. From Figure.11it can be observed that, at the low voltage ranges metal removal rate is high and at the higher voltage range metal removal rate is low. However, application of very low values promotes arcing tendency. Higher values of gap voltage can causes relatively lower removal rates. This is in opposition to the previous study carried out on electric discharge machining of mixed alumina based ceramic with titanium carbide composites (Ko-Ta Chiang, 2008), where it was stated that increase in voltage leads to increase in metal removal rates, however the effect of voltage on tool wear rate and surface roughness is in agreement with the previous study carried out on the electric discharge machining of composites (Narender singh et al., 2004).

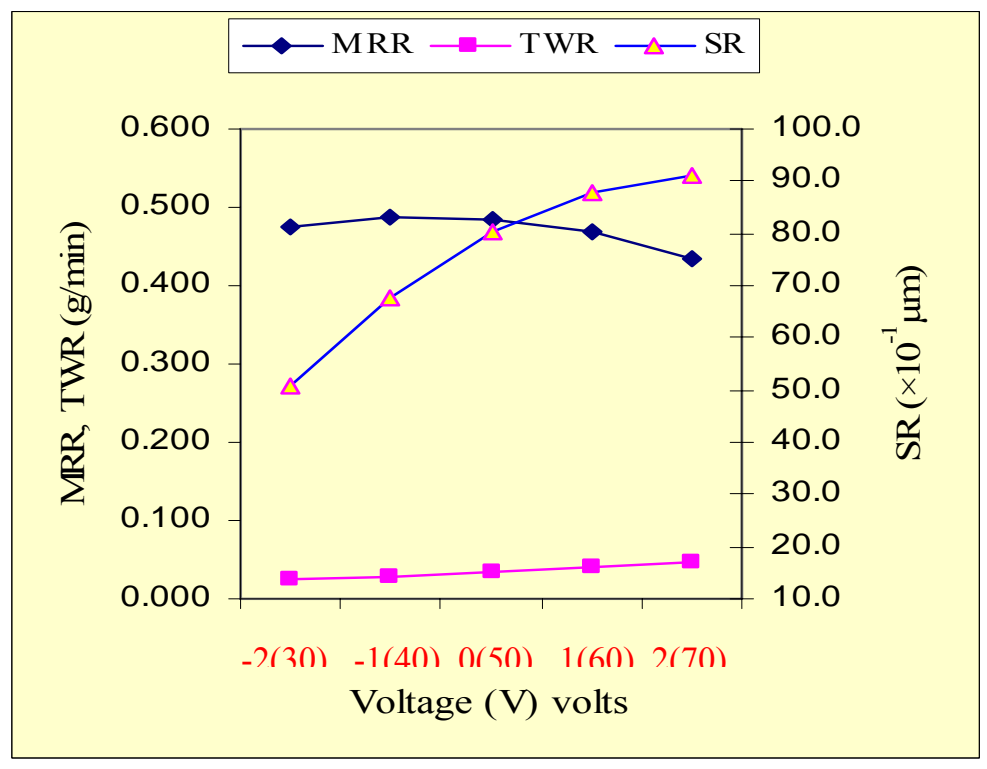

Figure 11: Effect of voltage on the response variables 


\subsubsection{Effect of flushing pressure $(\mathrm{P})$ on response variables}

In electric discharge machining, flushing is of very much importance, since the dielectric flushing of the spark gap keeps the gap clean and removes spark eroded particles continuously from the gap. It has a great influence on machining stability, which in turn affects the removal rate and tool wear rate. From Figure 12 it is found that the dielectric flushing pressure has positive effect on metal removal rate and surface roughness. The metal removal rate and surface roughness increases with the increase of dielectric flushing pressure. This is because when the flushing pressure is low, flushing cannot remove the gaseous and solid debris adequately after each discharge and the dielectric is increasingly unable to clear away the molten material, causing it to build upon the surface of the parent material. Further, the increase of the flushing pressure decreases the tendency for arcing and increases the metal removal rate. The tool wear rate decreases with increasing flushing pressure. This is possibly due to the increase in cooling rate of the tool with increase in flushing pressure. The similar observation has been confirmed by the previous researchers Narender singh et al., 2004; El-Taweel, 2009; Muller and Monaghan, 2000.

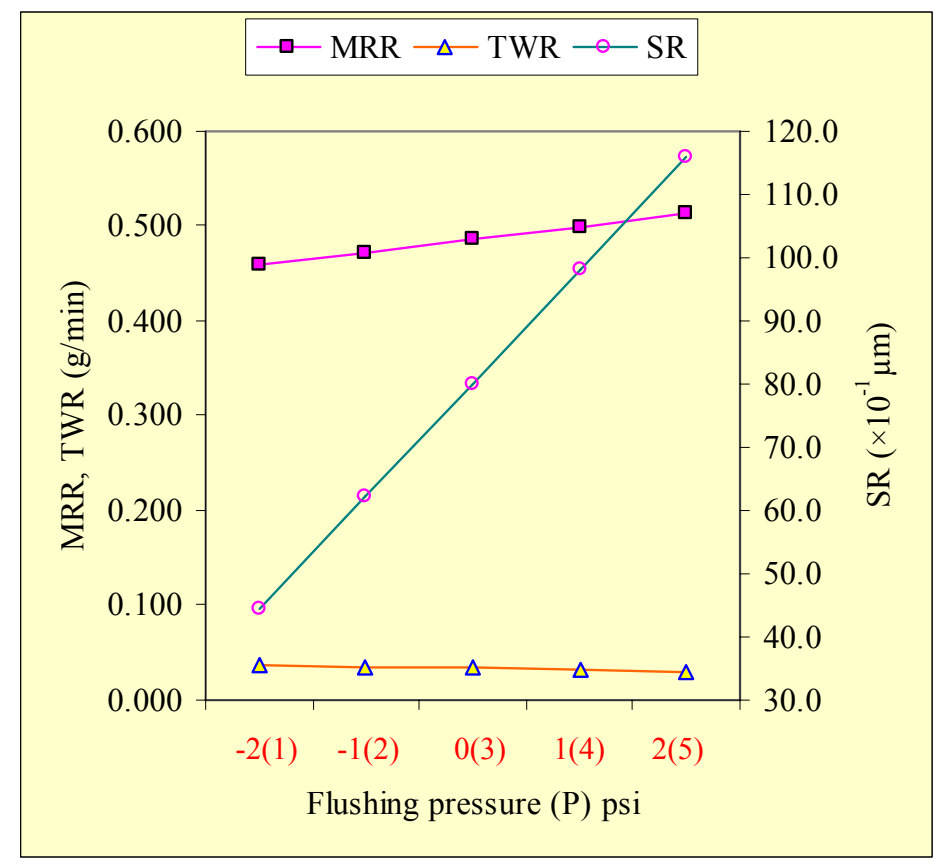

\section{Conclusions}

Figure 12: Effect of flushing pressure on the response variables

- Metal removal rate of the composite increases with increase in current, pulse on time and flushing pressure of the dielectric fluid while it decreases with increase in voltage.

- Tool wear rate of the developed composite increases with increase in current and voltage and it decreases with increase in pulse on time and flushing pressure of the dielectric fluid.

- Surface roughness of the composite during electric discharge machining increases with increase in current, pulse on time, voltage and flushing pressure.

- It is found that all the four machining parameters have significant effect on the response variables considered in the present study.

\section{References}

Cochran G. and Cox M. 1987. Experimental designs. John Wiley\&sons, Newyork.

El-Taweel T.A. 2009. Multi-response optimization of EDM with $\mathrm{Al}-\mathrm{Cu}-\mathrm{Si}-\mathrm{TiC} \mathrm{P} / \mathrm{M}$ composite electrode. International Journal of Advanced Manufacturing Technology, 44, pp.100-113. DOI 10.1007/s00170-008-1825-6.

George P.M. Ragunath B.K. Manocha L.M. and Warrier A.M., 2004. EDM Machining of carbon-carbon composites-a taguchi approach. Journal of Materials Processing Technology, 145(1), pp.66-77.

Gunaraj V. and Murugan N. 1999. Prediction \& comparision of the area of the heat effected zone for the bead on plate \&bead on joint in submerged arc welding of pipes. Journal of Materials Processing Technology, 95, pp.246-261.

Harris P. and Smith B.L. 1983. Factorial technique for weld quality prediction. Met construct,15: pp.661-666. 
Kao J.Y. Tsao C.C. Wang S.S. and Hsu C.Y. 2009. Optimization of the EDM parameters on machining Ti-6Al-4V with multiple quality characteristics. International Journal of Advanced Manufacturing Technology, DOI 10.1007/s00170-009-2208-3.

Ko-Ta Chiang. 2008. Modeling and analysis of the effects of machining parameters on the performance characteristics in the EDM process of Al2O3+TiC mixed ceramic. International Journal of Advanced Manufacturing Technology, 37, pp.523-533. DOI 10.1007/s00170-007-1002-3.

Khanra. A.K. 2005. Electrical discharge machining behavior of hotpress $\mathrm{MoSi}_{2}$. Journal of Materials science, pp.3027-3030.

Kuppan P. Rajadurai A. and Narayanan S. 2006. Experimental investigation into electrical discharge deep hole drilling of Inconel 718 using graphite electrode. In: proceedings of the $17^{\text {th }}$ All India Machine Tool Design \& Research Conference, PP.923-927.

Kannan T. and Murugan N. 2006. Effect of flux cored arc welding process parameters on duplex stainless steel clad quality. Journal of Materials Processing Technology, 176, pp.230-239.

Kuang-Yuan Kung . Jenn-Tsong Horng \& Ko-Ta Chiang, 2009. Material removal rate and electrode wear ratio study on the powder mixed electrical discharge machining of cobalt-bonded tungsten carbide. International Journal of Advanced Manufacturing Technology, pp.95-104.

Leesh and Li Xp. 2001. Study of the effect of machining parameters on the machining characteristics in electrical discharge machining of WC. Journal of Materials Processing Technology, 115(3), pp.344-358.

Lauws. Yue T.M. Lee T.C and Lee W.B., 1999. Unconventional machining of composite machining. Journal of Materials Processing Technology,48, pp.199-205.

Mahdavinejad R.A. and Mahdavinejad A. 2005. Electric discharge machining of WC-CO. Journal of Materials Processing Technology, 163, pp.637-643.

Murugan N. and Parmar R.S. 1995. Mathematical models for bead geometry prediction automatic stainless steel surfacing by MIG welding. International journal of joining of Materials, 7, pp.71-80.

Montgomery D.C. 2003. Design \& Analysis of Experiments. 5th edition, John Wiley\&Sons (Asia) Ltd.

Mihaly Kozma., 2003. Friction and wear of aluminum matrix composites. National tribology conference ROTRIB'03.The Annals of university "Dunarea De Jos" of galatiFascicle VIII, 2003 ISSN 1221-4590, pp.99-106.

Muller F. and Monaghan J. 2000. Non conventional machining of particles reinforced metal matrix composites. International Journal of Machine Tools Manufacturing, 40, pp.1351-1366.

Narender singh P. Raghukandan K. Rathinasabapathi M. and Pai B.C. 2004. Electric discharge machining of Al-10\% SiCp as-cast metal matrix composites. Journal of Materials Processing Technology, 155-156, pp.1653-1657.

Nilesh Ganpatrao Patil \&Brahmankar P. K. 2010. Determination of material removal rate in wire electro-discharge machining of metal matrix composites using dimensional analysis. International Journal of Advanced Manufacturing Technology, pp.599610.

Ponappa K. Aravindan S. Rao P.V. Ramkumar J. and Gupta M. 2009. The effect of process parameters on machining of magnesium nano alumina composites through EDM. International Journal of Advanced Manufacturing Technology, DOI 10.1007/s00170-009-2158-9.

Patel K. M. Pulak M. Pandey \& Venkateswara Rao.P, 2010. Optimisation of process parameters for multi-performance characteristics in EDM of Al2O3 ceramic composite. International Journal of Advanced Manufacturing Technology, pp.11371147.

Rosso M., 2006. Ceramic and metal matrix composites: Routes and properties. Journal of Materials Processing Technology, 175, pp.364-375.

Riaz Ahamed.A. Asokan. P \& Aravindan.S, 2009. EDM of hybrid Al-SiCp-B4Cp and Al-SiCp-Glassp MMCs. International Journal of Advanced Manufacturing Technology, pp.520-528.

Surappa M.K., 2003. Aluminum matrix composites: challenges and opportunities. Sadhana, Vol (28), parts 1\& 2,pp.319-334, printed in India.

Simul Banerjee, Pebasish Mahapatro, and Shishir Dubey. 2008. Some study on electrical discharge machining of $((\mathrm{WC}+\mathrm{TiC}+\mathrm{TaC} / \mathrm{NbC})-\mathrm{Co})$ cemented carbide. International Journal of Advanced Manufacturing Technology, doi10.1007/S00170008-1796-7.

Torralba J.M. Dacosta C.E. and Velasco F., 2003. P/M aluminium matrix composites: an overview. Journal of Materials Processing Technology, 133, pp.203-206.

Velmurugan C. Subramanian R. Thirugnanm S. Kannan T. and Anandavel B. 2011. Experimental study on the effect of SiC and graphite particles on weight loss of Al6061 hybrid composite materials. Journal of Tribology and Surface Engineering, Vol.2, pp.49-68.

\section{Biographical notes}

C.Velmurugan is working as Senior Associate Professor in the Department of Mechanical Engineering at Kumaraguru College of Technology, Coimbatore. He has completed B.E (Mechanical Engineering) and M.E (Engineering Design) with First class with Distinction. He has completed PhD in the area of machining of composites. He has published 15 papers in the conferences and organised two national level workshops and one three days national conference. He is serving as a member in Board of Studies in the Department of Mechanical Engineering at Kumaraguru College of Technology. He is a life member in Indian Society of Technical Education. His main interest field is wear property improvement and machinability studies for composite materials. 
R.Subramanaian is working as Associate Professor in the Department of Metallurgical Engineering at PSG College of Technology, Coimbatore. He has an experience of 23 years in teaching in the field of Metallurgical Engineering. He has completed $\mathrm{PhD}$ in the area of composite materials. His areas of interest are physical metallurgy, powder metallurgy and nano materials. He has published 27 papers in international, national journals and conferences. He has organised a national conference on quality control in metallurgical industries. He received best project award for the year 1992-1993 from Director of Technical Education, Tamilnadu. He has got research funding to the tune of about 1 crore from DST, DRDO and TATA STEEL. Currently he is guiding 7 researcher scholars. He has co authored two books.

S.Thirugnanam is working as Professor and Head in the Department of Mechanical Engineering at Valliammai Engineering College, (a member of SRM Group) Kanchipuram, India. He obtained his Bachelor's degree in Mechanical Engineering from Madurai Kamaraj University, India in 1990. He obtained his Master's Degree in Production Engineering from Bharathiar University, India in 1993. He received his Ph.D. Degree for his work on the innovation management of Quality circles, ISO 9001:2000 and TFMEA from the same university in 2003. He has five years of company experience and twelve years of teaching experience. He has published over 15 papers in the proceedings of the leading national and international conferences. His areas of interest include Total Quality Management (TQM) and Materials Engineering.

B.Anandavel is working as Assistant Professor in the Department of Metallurgical Engineering at PSG polytechnic college. He has completed B.E (Metallurgical Engineering) and M.E (Industrial Metallurgy) under Anna university Chennai.

Received November 2011

Accepted January 2012

Final acceptance in revised form March 2012 